\title{
Credit Risk Transfer and Financial Stability: A Survey
}

\author{
Lili ZHOU \\ School of Economics and Management, \\ Nanchang University, Nanchang, China \\ Email: zlljody@163.com
}

\author{
Qing CHEN \\ Yiwu Industrial \& Commercial College, \\ Yiwu, China
}

\begin{abstract}
The relationship between credit risk transfer and financial stability were reviewed from two perspectives of the individual banks and financial system in this paper, in which focusing on the instruments of credit risk transfer and the incentive to monitor loan, as well as the differences of measurement methods and analytical conclusions. Finally, brief comments.
\end{abstract}

Keywords-credit risk transfer; financial stability; systemic risk

\section{Introduction}

Credit risk transfer (CRT) refers to the bank transfer credit risk to other banks or financial institutions through various financial instruments, risk transfer behaviors from direct loans sales to the credit derivatives without specific subject, all belong to the CRT. The basic principles of CRT is to allow a relatively weak financial institutions to transfer risks to other financial institutions, so that the concentration risk can be diversified, which is the main reason that regulatory agency initially recognized the risk transfer behavior (IMF, 2008). Risk analysis methods used by regulatory agency in the past generally only consider the risk capital of the bank's own, while ignoring the increase in systemic risk. In fact, the effect of credit risk transfer on financial stability is mainly reflected in the changes in the financial systemic risk, which is not the same as systematic risk. Systemic risk is known as the financial system instability in the financial sector, mainly refers to when the adverse events occurred, the risk of the financial institution as a whole may be running failure, is not frequent and caused by more extreme events. Systematic risk refers to the risk that can not be dispersed, and closely related to the economic factors of overall market, such as the yield. Banks transferred credit risk to the financial system through various channels, increased the intensity of the financial crisis, which is an important feature of financial crisis in 2008 different from the past. Clearing the effect of CRT on the financial stability, and effectively measuring the extent of the impact of CRT on the financial stability, is the fundamental of regulating the CRT behavior and maintaining financial stability.

The research of impact of credit risk transfer on financial stability can be divided into two aspects: one analyze CRT behavior from a single bank perspective, compare the behavior of banks before and after CRT using the tool of cost-benefit analysis in connection with the tool chose and regulatory willingness of banks participated in the CRT market, point out the ways that may affect the financial stability to provide reference for the regulatory agency to management financial market effectively; The other analyze CRT behavior from financial system perspective, general sampling from the representative financial institutions, focused on exploring the key variables affecting the financial stability, measure the impact of CRT on financial stability by constructing model, aims to clear the degree, direction and other details of impact of CRT on financial stability, in order to provide policy basis of maintaining financial stability.

\section{Perspective of the banking behavior}

Liquidity and capital requirements are generally considered to be the main motive for bank loan sales and securitization, since the bank's capital is restricted under the pressure of the lowest risk capital formulated by regulatory agency (Chiesa, 2008) ${ }^{[1]}$. The research of impact of credit risk transfer on financial stability from perspective of the banking behavior mainly involves two aspects: choice of CRT tools and change in supervision willingness.

\section{A Choice of CRT tools}

In the issuance of commercial loans, lenders focus is to know the explicit solvency by understanding the borrower's overall financial position. It is necessary to consider two aspects in the issuance of CRT product, first is no harming the business relationship between borrowers and lenders; second, compared to CRT participants, the original lender has transaction information superiority, the participants may be concerned that the original lender to hide negative information of the borrower, resulting in adverse selection. CRT behaviors arise with the development of security design, the purpose of banks and financial institutions designing securities and loans transfer tool is to reduce the cost of risk transfer (Minton et al., $2009)^{[2]}$, so that analysis the choice of CRT tools is simply clear the difference of the bank motives, if the CRT tools selection and use is improper, will result in increased financial systemic risk. For the choice of tools, those high-risk banks bias in favor of the loan sales or securitization rather than credit derivatives in the pressure of asymmetric information and regulatory. In addition, banks with lower profit margins often want to participate in the CRT market to increase profitability at the same time to avoid credit risk.

\section{B Change in supervision willingness}

Supervision willingness mainly refers to the effective supervision and management of the bank loans or other subject of assets to reduce the probability of debtor default, the banks exercise supervision authority need to take the costs of project quality audit and monitoring. The change of Banking supervision willingness before and after the CRT 
often vary with different CRT tools, the financial systemic risk would rise when banking supervision willingness reduce or invalid. At this point the focus of analysis is not the choice of CRT tools, but the cost-benefit issues of different tools, in which the effectiveness of information transmission is the fundamental issue lead to changes in the willingness of the banking supervision.

The most obvious differences of impact on willingness of banking supervision in CRT tools is loan sales and credit derivatives, since assets and regulatory rights together transfer to others in loan sales, regulatory rights credit derivatives reserve by the original issue bank who buy a credit risk protection to loans. The analysis of relative literature of this problem in general basis on the ideal state of the CRT market, derive conclusion close the realistic through continuous relax assumptions. Common assumptions conclude: net present value of the project that the enterprise plans to invest are positive to a certain probability; the project funds loans from the banks; there is competition among banks in lending market; the bank can get real-time information on project progress after granted loans. The main difference between Loan sales and credit default swaps (CDS) is ownership and right to dispose of the loans in the CDS is retained by the bank, however the right to dispose of the loans in loan sales is transferred to the purchaser. The right of disposal need cost to perform, it will reduce the probability of default of the loan under appropriate conditions, and the key to perform it(i.e., regulatory) validly is the private information of bank get from lenders(Parlour and Plantin, 2006) ${ }^{[3]}$. Optimal credit risk transfer should be the form of securitization of the loan portfolio as a whole, and the regulatory agency should restrict credit enhancement, otherwise it will reduce the supervision willingness.

\section{Perspective of the financial system}

Although the overall situation of current credit risk transfer market is relatively clear, but the CRT data are often nominal, and can not act as guide of risk in complex CRT products (Ashcraft and Santos, 2009) ${ }^{[4]}$ 。 It is a good example that some company's risk exposure sharp spike in the 2008 subprime crisis. Thus the research of the impact of CRT on the financial stability from the perspective of the financial system in general face the problems that acquisition channels and accuracy of the empirical data.

\section{A Difference in measurement methods}

\section{1) Financial stability description.}

There are many factors causing financial system turmoil, such as credit risk contagion, market imperfections, macroeconomic environment, and so on, to describe the characteristics of financial stability with a model is very difficult and make model too complex. Constructing the model to reflect the different risk is often based on different needs in the actual analysis. The majority of the literatures exploring the impact of credit risk transfer on the financial stability describe the financial stability through yield correlation coefficient among financial institutions or beta coefficient.

In the study of financial system stability considered from the perspective of correlation, Instefjord (2005) pointed out that the bank can hedge the credit risk and expected distress costs through the derivatives market, and he built the optimal commercial bank credit risk models based on asset correlation. In the case of Marsh (2006) estimated the relevance of the inter-bank portfolio from a global perspective on the assumption that the existence of one ultimate lender.

Beta coefficient, known as Beta value, is a indicator used to measure the systemic risk of an asset, refers to volatility a securities or an investment portfolio relative overall market. Krahnen and Wilde(2006) as the representative of the literature analyzing the stability of the financial system from the perspective of bank equity beta value, suggests that the beta value of banks rise mainly due to two aspects: first, the risk orientation of bank funds released the through securitization did not reduce; second, equity layer of derivatives are retained by the issuer. The Merton model has generally been used in these literatures to describe the changes in value of bank assets:

$$
V_{n, t}=\sqrt{\rho_{n}^{M}} Y_{t}^{M}+\sqrt{1-\rho_{n}^{M}} \varepsilon_{n, t}
$$

In equation (1), the company value $V_{n . t}$ were affected by macroeconomic factor $Y_{t}^{M}$ and company-specific factors $\varepsilon_{n, t}, n$ and $t$ means a specific financial institution and the time point. Thus the yield of specific layer such as middle class will be:

$$
r=\alpha+\beta Y_{M}+\varepsilon
$$

The beta value is influence coefficient of macroeconomic factor $Y_{M}$ on yield $r$. And then decompose the beta value, focusing on analysis of difference before and after securitization:

$$
\beta_{\text {assets }}=\beta_{\text {debt }} d+\beta_{\text {equity }} e
$$

The beta value $\beta_{\text {assets }}$ of the company assets equal to the beta value of the debt component $\beta_{\text {debt }}$ plus beta value $\beta_{\text {equity }}$ of equity component. If the beta value is increased after the credit risk transfer, indicates the increase of systemic risk. The equity beta changes after the transfer of credit risk as follows:

$$
\begin{aligned}
& \Delta \beta_{\text {equity }}=\beta_{\text {equity }}^{\text {new }}-\beta_{\text {equity }}^{\text {orig }} \\
& =\frac{\beta_{\text {assets }}^{\text {new }}}{e^{\text {new }}}-\frac{\beta_{\text {assets }}^{\text {orig }}}{e^{\text {orig }}}-\frac{\beta_{\text {debt }}^{\text {new }} d^{\text {new }}}{e^{\text {new }}}+\frac{\beta_{\text {debt }}^{\text {orig }} d^{\text {orig }}}{e^{\text {orig }}}
\end{aligned}
$$

$\beta^{\text {orig }}$ in (4) denote the beta value before CRT, $\beta^{\text {new }}$ denote the beta value after CRT.

However, the correlation coefficient calculated according to a large number of observations is not suitable to explain the extreme events with small sample. Beta value of asset described the extent of individual bank exposure to systemic risk; it is difficult to effectively explain the overall stability of 
the financial system. Visible description of the financial stability remains to be improved.

\section{2) Model specification.}

It is necessary to build an appropriate model to describe the relationship between the CRT behavior and financial stability after specified financial stability variable. Commonly used model in the current literature, including vector autoregression (VAR) model, event study model, logic regression model, and capital asset pricing model (CAPM), in which the VAR model and event study model is the recognized by majority of literature. The general form of the VAR model in the relevant literature is:

$$
Y_{t}=c+\Phi_{1} Y_{t-1}+\Phi_{2} Y_{t-2} \ldots+\Phi_{p} Y_{t-p}+\varepsilon_{t}
$$

Endogenous variables $Y_{t}=\left(y_{1 t}, y_{2 t}, \ldots, y_{n t}\right)^{\prime}$, the vector can include the stock price response to yield changes, government bond yields the response to macroeconomic environment can affect the stock price, the price of equity layer, the majority of the middle layer and part of the prior layer in Collateralized Debt Obligations(CDOs) response to risk. The higher volatility of the prior layer yield, the lower impact of company's credit risk exposure on financial stability, because of the diversification of decentralized risk. Jorge et al. (2006) analyzed Britain's CRT market through the VAR model, the results showed that the impact of the credit derivatives on the stability of financial institutions is not significant. Franke and Krahnen (2005) studied on the credit loss distribution which is stratified truncated from the perspective of the CDO layered using the VAR model, also considered asset correlation and systematic risk exposure change. Hänsel and Krahnen(2007) believes that the impact of credit risk transfer depends on the substitution effect: if the risk bank transferred out is substituted by low correlation asset, then the bank's equity beta value will drop. They used the event study method which has been recognized by a lot of papers:

$$
\begin{aligned}
& R_{i t}=\alpha_{i}+\beta_{1 i} R_{M}+\gamma_{1 i} D^{\text {event }}+\gamma_{2 i} D^{\text {otherevent }} \\
& +\beta_{i}^{\Delta} D_{i}^{\text {after }} R_{M}+\beta_{2 i}\left(R_{B}-R_{M}\right)+\varepsilon_{i} \\
& R_{i t}, R_{M}, R_{B} \text { in (6) respectively denote the yield of }
\end{aligned}
$$
securities, the market portfolio yield and the yield of the Dow Jones STOXX index (if study in other regions, you need to use the appropriate representative index, such as Morgan Stanley's MSCI index, Germany's DAX index), $D^{\text {event }}$ 、 $D^{\text {otherevent }}$ and $D_{i}^{\text {after }}$ are all dummy variables, are set to be 1 if they located in specified fluctuation interval of insurance time. $\beta_{1 i}$ is systemic risk to be estimated. Briefly, if the beta value less than 1 , systemic risk will rise after CRT, and vice versa will drop. The relationship between the bank beta and CDO issuance can be get from the cross-sectional regression in which the dependent variable beta value estimator come from panel regression.

\section{B Conclusion of empirical Analysis}

\section{1) Dual impact on financial stability.}

Most of the studies recognized that the CRT has dual impact on financial stability. On one hand, appropriate risk transfer can reduce the risk of the bank itself, on the other hand, however, banks often will response to the risk reduction in the process of CRT, hidden the information of risk transfer, reduce the cost of supervision, transfer risk, loan to higher risk project to get higher interest, all these behaviors damaging to the welfare of others will affect the financial stability. The current financial market turmoil also shows that the securitized asset markets and the capital markets on which trading assets may malfunction. In short, the bank found that the risk had been transferred out back on their own balance sheet.

\section{2) Enhance financial stability.}

Some studies are more optimistic about the effect of CRT, they thought that the CRT behavior makes the banks are able to spread and reduce risk, not only improve the liquidity, but also conducive to the enhancement of the overall market value. Wagner and Marsh (2006) pointed out that too many risky assets banks holding lead to high social costs borne by the financial system, credit risk is transferred to the non-bank financial institutions hold less risky assets and with investment demand, not only improve overall well-being, but also conducive to financial stability.

\section{3) Weaken financial stability.}

Some studies suggest that credit risk derivative transactions within the financial system have changed the expectations of the traders on the degree of information asymmetry, and thus adversely affect the financial stability. Similar literature also think that in the incomplete market, CRT are more likely to increase the concentration of risk(Keys et al., 2008), rather than dispersion. For example, in the United States, banks who bought insurance through credit derivatives expanded the size of loans(Hirtle, 2009) ${ }^{[5]}$, enhanced the bank's asset-liability ratio, eventually lead to an increased risk of the financial system.

Overall, analysis the CRT behavior from the perspective of financial systemic risk, the advantage lies in one can study the details of impact based on actual data, and can evaluate the model's predictive ability. However the relevant statistical data is not entirely credible, such as volume and price of CRT products the bank actual merchandise. Although the results of event study method are relatively accurate, but it require the detailed information of the data, so application is often subject to data problems.

\section{Brief comments}

Foreign literatures have important reference value on the development of the CRT market and maintaining financial stability in China, but from the actual point of view, the measurement of CRT on the financial stability is not complete, and the credit risk management techniques has big gap with developed country. This paper believes that future research should pay attention to two aspects: firstly, a lot of papers focus on the analysis of individual banks and the banking system when study the CRT behavior. In fact within the 
financial system, links between banks and insurance companies increasingly close, insurance companies in Europe and America is the largest recipient of credit risk outside the banking system, which is the largest seller of the risk protection(ECB, 2008)。With the development separation and re-synthesis technology of credit risk, the pattern credit risk transfer from the banking sector to the other participants will be more flexible. So that the sample should also include large insurance companies and banks Insurance Group in addition to the major banks when measuring financial systemic risk; secondly, we should not only make circulation of CRT products (such as CDO, CDS, etc.) as the main factors in the analysis of credit risk transfer on financial stability, but also consider other macro risk factors. Although there are a lot of papers have proposed the introduction of observable macroeconomic variables to explain changes in the financial systemic risk, but the results showed that only the use of observable variables is far from satisfying, and which macro-covariates to use is also a controversial issue. If the macroeconomic covariates tend to be used, auxiliary prediction model need to be built on these variables, but to increase the complexity of the model. Thus, only joined the observable macroeconomic factors is difficult to solve the problem, ignoring the macroeconomic covariates will reduce the inferred accuracy, future research can try to apply the latent factor to describe changes in the macroeconomic environment (Wagner, 2008)。In addition, differences of samples from different literature are very large, making a lot of literature are based on the characteristics of the data to determine the model form, so that lack of a uniform standard to compare different models predict ability which should be addressed in the future.

\section{References}

[1] Chiesa, G. Monitoring-Enhancing Credit Risk Transfer: The Incentives for Banks[J]. Journal of Financial Intermediation, 2008, 17(4): 464-477.

[2] Minton, B.A., R. Stultz, R. Williamson. How Much do Banks Use Credit Derivatives to Reduce Risk?[J]. Journal of Financial Services Research, 2009, 35(1): 1-31.

[3] Parlour, C.A., G. Plantin. Loan Sales and Relationship Banking[J]. Journal of Finance, 2007, 63(3): 1291-1314.

[4] Ashcraft, A.B., J. Santos. Has the CDS Market Lowered the Cost of Corporate Debt?[J]. Journal of Monetary Economics, 2009, 56(4): 514-523.

[5] Hirtle, B. Credit Derivatives and Bank Credit Supply[J]. Journal of Financial Intermediation, 2009, 18(2): 125-15 